\title{
THE NUFFIELD UNIT OF TROPICAL ANIMAL ECOLOGY
}

$I^{\mathrm{N}}$

the past few years biologists in general have come 1 to realize the great importance of an intensive study of tropical animals, their ecology, and the conditions of their existence. It is not merely that tropical Nature is a source of invaluable scientific information which is in danger of vanishing through the changing of the face of the Earth by man. It is also that the fauna of tropical nature reserves gives us an opportunity of determining with precision the factors that control both the physiology of individual animals and the size of their populations under conditions as yet relatively unspoilt. We need critical analysis of ecological factors, aided by laboratory investigations, together with the physiological study of what makes tropical species so much more efficient for the production and maintenance of animal substance than species imported from temperate latitudes.

It was with studies of this sort in mind that, on the initiative of Sir Landsborough Thomson and the Zoological Society, in discussions with the Director of the Nuffield Foundation, a proposal to form a Unit of Tropical Ecology was developed and placed before the Foundation. The Foundation has accepted the proposal and given it most generous and substantial support. The University of Cambridge has readily accepted the proposal that the Unit should be controlled from the University.

The immediate objective of the Unit is to maintain one senior and one junior research worker in tropical ecology to work at the Queen Elizabeth National Park, where the Trustees of the Uganda National
Parks already have a small field station. The work of the Unit will, however, be controlled from the University of Cambridge, by a Committee under the honorary chairmanship of Prof. C. F. A. Pantin. The Committee will include representatives from the University of Cambridge, the Nuffield Foundation, the Zoological Society of London and the Trustees of the Uganda National Parks. It is an important part of the scheme that, while the field work will be done in Uganda, the research workers will spend substantial periods planning their work and studying their observations in the Zoological Laboratory at Cambridge. It is hoped that as the scheme develops other research workers will be encouraged to attack problems in Uganda, and also that it will lead to young research workers engaged on such problems coming to work at Cambridge. The authorities of Makerere College have already shown great interest in the Unit.

The Committee will be holding its first meeting early this year to consider staff appointments, and sent Dr. Hugh B. Cott to visit the field station in December and to make a first report. The promoters of the scheme have great hopes that the Unit will lead not only to important work on the ecology, physiology and environmental relations of tropical animals, but also to a greater contact between research workers in Britain and Uganda than has hitherto been possible: further, that the attack on animal ecology may later develop into a broader project, including plant ecology and the study of micro-organisms.

\section{BRITISH COMMUNICATIONS SATELLITE PROGRAMME}

\begin{abstract}
TN replying for the Government in an adjournment debate in the House of Commons on December 21 on a British communications satellite programme, which had been opened by Mr. A. Neave, Mr. G. Rippon, the Parliamentary Secretary to the Ministry of Aviation, welcomed the practical approach of speeches in the debate. Previously he had pointed out that communications satellites involve the use of a powerful launcher and that the project is thus distinct from the programme based on Skylark, the giant programme in the United States, and also the Preparatory Commission set up to study the possibility of establishing a European space research organization. Both British and American experts are confident that the purely technical problems can be solved within the next few years, and Post Office and Ministry of Aviation scientists and engineers are already carrying out joint work on the design of ground stations and satellites as well as of overal system design. This work is concerned with both technical and economic aspects of satellites. While the co-operation of industry will be sought at the appropr ate stage, he did not think that there is anything to be gained by setting up a space communications committee at Cabinet level, as suggested by Mr. Neave.
\end{abstract}

Mr. Rippon pointed out that many different types of system have been proposed, but experts, both in the United States and in Britain, to-day appear to favour a system using active satellites which will carry radio receivers and transmitters, thus receiving, amplifying and re-transmitting signals instead of just reflecting. He promised to bear in mind what Mr. D. Price had said as to the possibilities of such a system.

The study of system design includes that of the type of orbit to be chosen for the satellites, which could be circular or elliptical, close to the Earth or far away. It is possible to choose a particular circular orbit for a satellite at about 22,000 miles from the Earth, and three such satellites could be so placed that one at least is visible and potentially available for communication purposes from every country in the world, except for certain limited areas near the poles. This system has some disadvantages, and it may well be better to have a larger number of satellites in closer orbit, for example, a dozen or two satellites at 5,000 or 6,000 miles, or 50 at 2,500 miles. Whatever orbit is chosen, there are formidable difficulties, and the technical problems to be overcome make estimates of cost necessarily speculative at this stage. Reliable information on the useful life of a 